\title{
Study on Optimization of Combined Parameters of Subdivision Water Injection Layer Sections in Ultra-high Water Cut Stage
}

\author{
Lin $\mathrm{Li}$ \\ No.3 Oil Production Plant of Daqing Oilfield Co. Ltd, 163318 Daqing, Heilongjiang Province, China
}

\begin{abstract}
After 50 years of exploitation, Block A has entered the development stage of the ultra-high water cut stage. Although the layer series of development has been subdivided and adjusted, the interlayer interference is still serious, imposing difficulties in development adjustment. Based on dynamic production data and monitoring data analysis, this paper applies multi-disciplinary reservoir description technology and introduces economic evaluation indicators to quantitatively analyze the variation coefficient of permeability within subdivided layer sections, the number of monolayer breakthrough series and sections, the number of small layers within a layer section, and the effect of sandstone thickness on the subdivision and adjustment effect, analyze the influence of well test period and operation costs on the economic benefits, and the optimize combined parameters of subdivision water injection layer sections. After field application, the utilization proportion of sandstone in the soil layer with the subdivided well permeability of less than $0.1 \mu$ $\mathrm{m}^{2}$ increased by 18.3 percentage points, and the average daily oil output per well in the surrounding wells increased by $0.3 \mathrm{t}$, effectively reducing the decline in output and increase in the water cut, and providing technical support for water flood fine potential tapping in the ultra-high water cut stage.
\end{abstract}

\section{Introduction}

In the high water cut stage of the oil fields, subdivision water injection is one of the effective measures to improve the effect of water injection in the late stage of high water cut in order to facilitate the quantitative study of the influence of the differences between layers on the water injection. HUANG Fusheng, ZHOU Lei, NIU Weimin [1-7] et al applied reservoir numerical simulation techniques to study the optimal classification of subdivision water injection for sandstone oil fields and improve and study the original water flood injection production adjustment standards in the late stage of ultra-high water cut in combination with the actual conditions of oil field development, considering the parameters such as well conditions, interlayers and so on, and cited the test technology of stratified flow of subdivision water injection pipe column wells; WU Yizhi [8] et al applied the reservoir numerical simulation to study the technical boundaries of the layer section combination; ZHANG Yurong, FU Qingchun [9-12] et al analyzed the law of interlayer interference in zonal injection, set up a parameter model considering the reservoir physical property, and gave a quantitative layered and quality-divided technical limits to control the rate of water cut rise, and reduce production decline, and studied the methods and criteria for subdivision water injection in the late stage of high water cut; GAO Hang, XIA Bing [13-15] et al. determined the general principles for layer recombination and refinement of layer series of development based on the current status of the well network and existing contradictions in the test area, and conduct research on adjustment of water flood development for the existing layer series and well network can no longer fully adapt to the needs of the development of this fault block oil reservoir, and YANG Zhonggui [16-17] et al applied matching technology for subdivided layers to improve the level of development of the target oil field according to the situation of subdivided zonal injection in the target oil field, and ensured the effective zonal injection in the implementation process by selecting valid parameters.

\section{Raise of problems}

In the ultra-high water cut stage of development of the oil field, the water cut difference between the layers will gradually become smaller and the high water cut well layers will gradually increase. The injected water will easily advance along the formed water-injection dominant channel to form a low efficient circulation of injection production, restraining the effective use of thin and poor layers and outside-delimited reservoirs, thus causing the intensified contradictions between layers and in the layer series. At present, the successive intensifying adjustments for different mining targets have been completed in Block $\mathrm{A}$ and the subdivision and adjustment has been completed for the layer series of development of the Pu-II high-oil reservoir. The contradictions between the layers are still prominent. From isotope water absorption data, the water absorption

\footnotetext{
* Corresponding author: lin_li@petrochina.com.cn
} 
ratio of sandstone and effective thickness is $74.6 \%$ and $78.9 \%$, respectively. Among them, the water absorption ratio of sandstone with an effective thickness of greater than $2 \mathrm{~m}$ and the effective thickness is $95.0 \%$ and $95.3 \%$ respectively, and the water absorption ratio of the outside-delimited reservoir is only $42.7 \%$. The utilization of middle and low permeability layers is seriously disturbed. Water flood development adjustment is based on enough and good water injection. In order to control the rate of water cut rise, reduce production decline, and maximize the exploration of remaining oil, it is necessary to optimize the parameters of the layer section combination according to the reservoir characteristics of the oil field in a rational manner, so as to improve the water flood development effect.

\section{Study on Reasonable Parameters in Zonal Injection Section}

In order to quantify the grading standard for subdivision water injection, the water injection conditions of 298 layered wells and 1,209 water injection layer sections with continuous water absorption profiles for water flood were investigated. The geological parameters of layer sections with different producing degrees were recorded to get the statistical law by which the producing degree was greater than $80 \%$. The main demarcation index for the study is the ratio of sandstone utilization thickness. The main parameters in the selected layer section under study include the relevant parameters reflecting the interlayer heterogeneity, the number of small layers in the sections, and the thickness of the sandstone in the sections.

\subsection{Effect of Interlayer Heterogeneity on the Utilization of Oil Reservoirs}

\subsubsection{The relationship between the permeability ratio and the oil reservoir utilization proportion}

The permeability level is a parameter that reflects the degree of heterogeneity in the layer section. The permeability ratio $=K_{\max } / K_{\min }$. The relationship between the permeability ratio and the utilization ratio of sandstone thickness is not obvious (Figure 1).

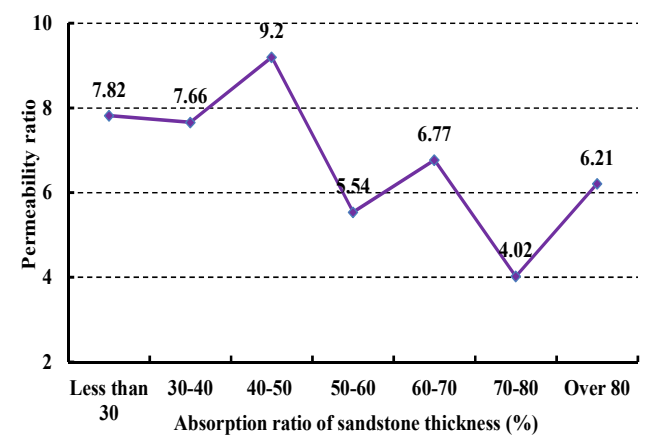

Fig. 1. Relationship between Permeability Ratio and Water Absorption Ratio of Sandstone Thickness.

\subsubsection{The relationship between interlayer variation coefficient and the oil reservoir utilization proportion}

The interlayer variation coefficient refers to the ratio of the mean square error of the permeability of the oil layers in the statistical layer section to the average permeability. The greater the value of the variation coefficient of permeability is, the stronger the interlayer heterogeneity is.

Mean permeability

$\bar{K}=\left(h_{1} k_{1}+h_{2} k_{2}+\cdots \cdots h_{n} k_{n}\right) /\left(h_{1}+h_{2}+\cdots \cdots h_{n}\right)$

Std dev

$$
\sigma=\sqrt{\left[\left(K_{1}-\bar{K}\right)^{2}+\left(K_{2}-\bar{K}\right)^{2}+\cdots \cdots\left(K_{n}-\bar{K}\right)^{2}\right] / n}
$$

Interlayer variation coefficient $K_{V}=\sigma / \bar{K}$.

From the relationship between the interlayer variation coefficient and the utilization proportion of sandstone thickness, the variation coefficient gradually decreases with the increase of the utilization thickness proportion. If the producing degree of oil reservoirs reaches over $80 \%$, the interlayer variation coefficient must be controlled below 0.72 (Figure 2).

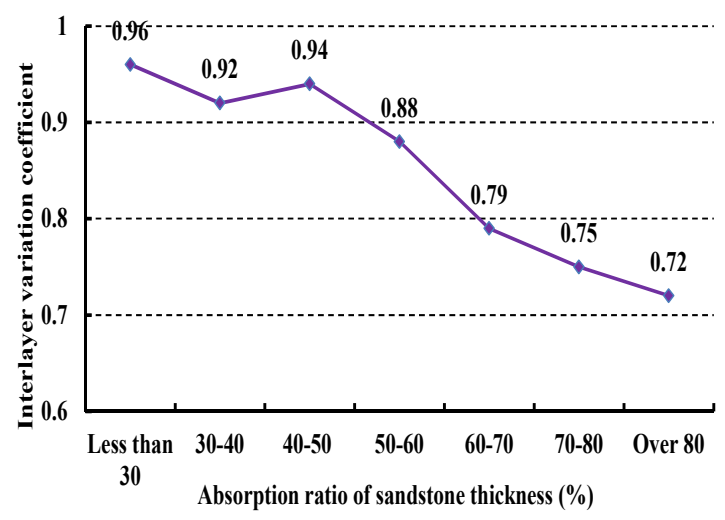

Fig. 2 Relationship between Interlayer Variation Coefficient and Water Absorption Ratio of Sandstone Thickness

\subsubsection{The relationship between interlayer variation coefficient and the oil reservoir utilization proportion}

The mutation coefficient reflects the degree of homogeneity of the oil reservoir within the section. The larger the value is, the stronger the interlayer heterogeneity is.

Coefficient of monolayer breakthrough $=K_{\max } / \bar{K}$.

It can be seen from the curve of the relationship between the mutation coefficient and the oil layer utilization thickness proportion that the sandstone utilization proportion increases with the decrease of mutation coefficient. If the producing degree of oil reservoirs reaches over $80 \%$, the mutation coefficient must be controlled below 1.23 (As shown in Figure 3). 


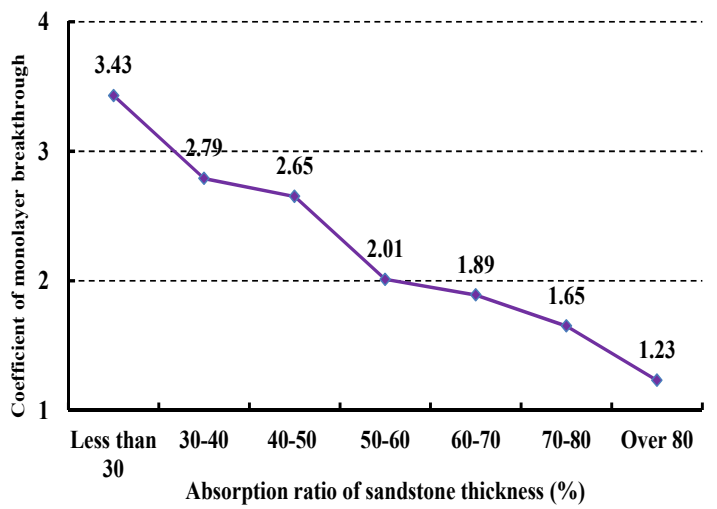

Fig. 3 Relationship between Coefficient of Monolayer Breakthrough and Water Absorption Ratio of Sandstone Thickness

\subsection{Effect of Number of Small Layers in the Layer Section on the Utilization}

It can be seen from the curve of the relationship between the number of small layers in the section and the sandstone thickness ratio that the sandstone utilization thickness proportion is gradually increasing with the decrease of the number of small layers in the section. When the number of layer sections decreases to 6 , the proportion of water absorption increases significantly with the further decrease in the number of layers. When the number of small layers within the layer section does not exceed 5, sandstone thickness utilization proportion is more than $80 \%$ (Figure 4 ).

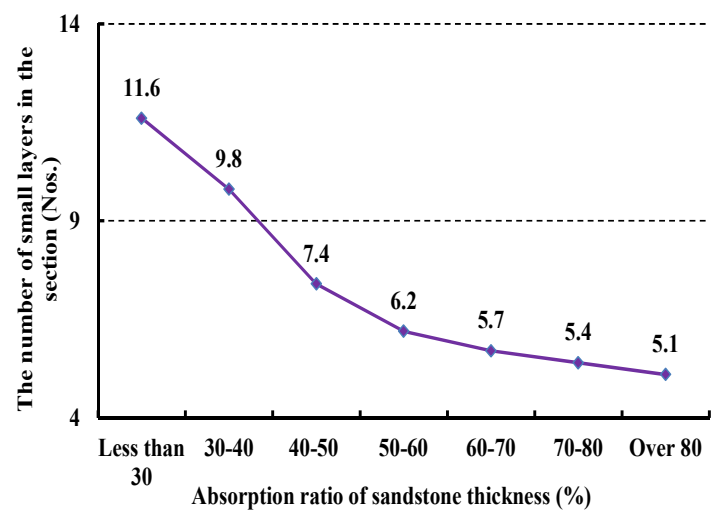

Fig. 4 Relationship between Number of Small Layers in the Section and Water Absorption Ratio of Sandstone Thickness

\subsection{Effect of Sandstone Thickness in the Layer Section on the Utilization}

It can be seen from the relationship between the thickness of sandstone in the section and the sandstone utilization thickness proportion that utilization thickness proportion gradually increases with the decrease in the thickness of the sandstone in the layer section. When the thickness of the sandstone in the layer section decreases to less than $6.5 \mathrm{~m}$, sandstone utilization thickness proportion reaches $80 \%$ (As shown in Figure 5).

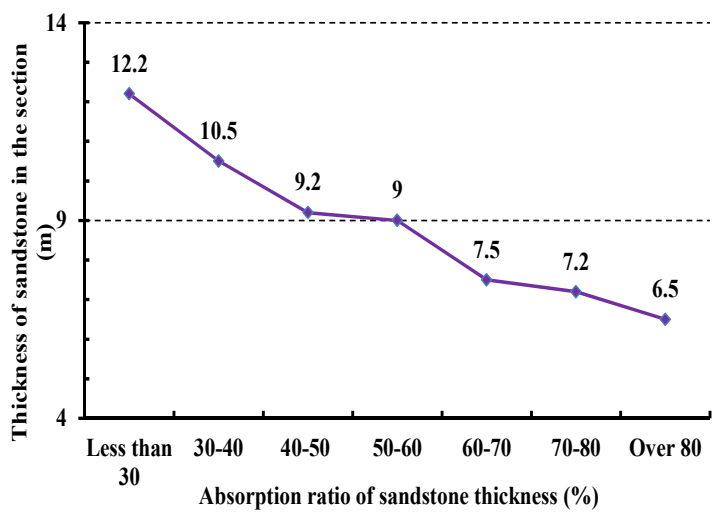

Fig. 5 Relationship between Thickness of Sandstone in the Section and Water Absorption Ratio of Sandstone Thickness

\section{Determination of the reasonable number of layer sections}

Theoretically, the more subdivisions of a water injection well are, the larger the increase in the oil recovery value is, but in the actual single well adjustment, the number of sections of a well to be subdivided is limited based on the parameters in the above-mentioned layer sections. The reasonable number of layer sections must take into account various factors such as development requirements, process conditions, testing techniques, and economic benefits. In order to meet the actual conditions of the oil reservoir, a water injection well model consisting of 30 small layers is designed to study the reasonable number of sections of the water injection well, the permeability ratio is set to be 25.00 for commingled water injection, 12.50 for that in the second section, 6.00 for that in the third section, 3.50 for that in the fourth section, 2.00 for that in the fifth section, 1.75 for that in the sixth section, 1.50 for that in the seventh section, and 1.25 for that in the eighth section. Through the simulation calculation, the increases of oil recovery ratio for the commingled water injection are $0.38,1.39,2.05$, $2.35,2.52,2.61$ and 2.71 percentage points respectively for the subdivided No. 2-8 sections. In view of the subdivision operating expenses, and costs for layered test and deployment during the validity period, and sealing test of the layer sections, when the water injection well is subdivided into 5 sections in the event of an oil price of USD 50, the input-output ratio reaches the maximum, so the reasonable number of sections is 5 from the economic analysis. 


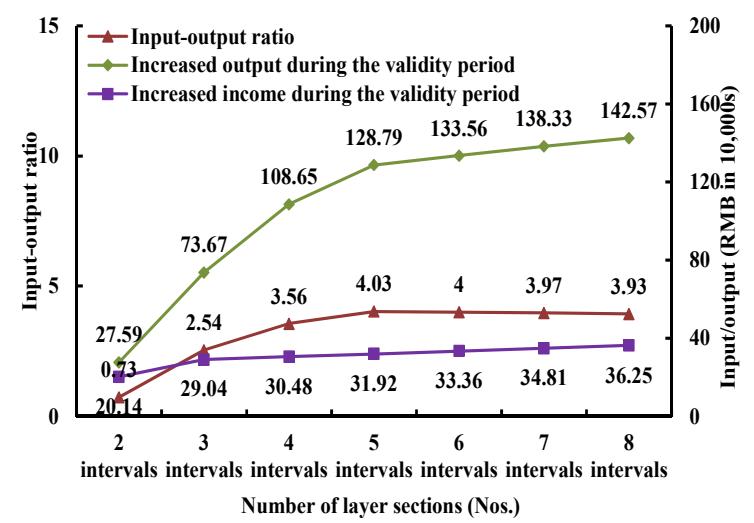

Fig. 6 Corresponding economic data for the different numbers of layer sections under the oil price of USD 50

\section{Matching technology for subdivision water injection}

Under the premise of satisfying various parameters within the layer sections, it is necessary to further improve the supporting technology to ensure the effect of zonal injection. The thin and poor oil layers are transformed before the subdivision through the fracturing measures to ensure that the water injection rate is increased after the adjustment; eccentric integrated water injection process is applied to subdivide the oil layers with the sandwich thickness of $0.6 \mathrm{~m}$ above; the constant flow blanking plug is applied to prevent the water injection rate in the high water cut layer section from being affected by the water injection pressure change, so that it is always kept constant to ensure that the water injection rate is controlled after the subdivision.

\section{Subdivision water injection effect}

According to the technical limits of subdivision water injection, 98 water injection wells were subject to subdivision and adjustment in the adjustment area, and 120 layer sections were added, with the water injection rate increased by $1,320 \mathrm{~m}^{3} /$ day. The average number of single-well water injection layer sections was adjusted from 3.64 to 4.86 , and the average number of small layers within the layer was 4.58 , which was 1.68 fewer than before adjustment. The average sand thickness in the section was $6.29 \mathrm{~m}$, decreased by $1.94 \mathrm{~m}$; the interlayer variation coefficient was 0.79 , decreased by 0.09 ; the ratio of the number of oil layers with the subdivided well permeability less than $0.1 \mu \mathrm{m}^{2}$ to the sandstone utilization proportion increased by 17.8 and 18.3 percentage points, and the average single-well production from the surrounding production wells increased by $0.3 \mathrm{t}$, effectively reducing the decline in production and the increase in water cut.

\section{Conclusions}

(1) Subdivision water injection can effectively alleviate the contradiction between layers, improve the utilization of oil layers, and control the decline of production. It is one of the most economical and effective water flood tapping technologies under the current bed set well pattern.

(2) In the preparation of the layer section subdivision scheme, if you want to obtain a utilization rate of over $80 \%$ in oil layers while considering the various factors such as the connection status of subdivided wells and production wells, oil reservoir development, casing damage protection, and long-time stopping layer recovery, the interlayer variation coefficient needs to be controlled below 0.72 , the mutation coefficient needs to be controlled below 1.23, the number of small layers in the layer section needs to be controlled within 5, the thickness of the sandstone in the layer section needs to be controlled within $6.5 \mathrm{~m}$, and meanwhile the number of layers to be subdivided should be controlled within 5 . Therefore, the wells with at most 5 sections are mainly subject to subdivision and adjustment, while those with more than 5 sections are mainly subject to restructuring and adjustment.

(3) The effective implementation of subdivision water injection in oil layers requires simultaneous development of multidisciplinary reservoir description technology, oil production technology, and testing and regulation technology.

\section{References}

1. HUANG Fusheng, ZHAO Yongsheng. Study on Optimal Hierarchical Simulation of Subdivision Water Injection in Sandstone Oil Fields in the High Water Cut Stage [J] Petroleum Geology \& Oilfield Development in Daqing, 1998, 7(2): 30-31.

2. ZHOU Lei. Re-determination of Technical Indicators for Waterflood Injection Production Adjustment in Lamadian Oilfield [J] Petroleum Geology \& Oilfield Development in Daqing, 2016, 35(4): 82-87.

3. NIU Weimin, XU Shao, and LV Mingjun. Zonal Flow Measurement Technique of Testing and Adjustment Integrated Subdivision Water Injection Wells [J]. Petroleum Geology \& Oilfield Development in Daqing, 2010, 19(3): 38-41.

4. LI Haifang. Effective Improvement of the Effect of Oilfield Development By the Use of Subdivision Water Injection Adjustment Method [J]. Inner Mongolia Petrochemical Industry, 2010, 12(2): 153158.

5. LV Yufeng. Research on Improving Development Effect Technology of Fuyu Oilfield in High Water Cut Stage [D]. Northeast Petroleum University, 2015.

6. LU Zhongyi. Research on the Development Effect of Oilfields after Improving the Medium to High Water Cut Period [J]. Chemical Engineering \& Equipment, 2017(10): 101-103.

7. LV Yiwen. Research on Improving Water Injection Development Effect of Huanbei Dujiatai Reservoir [D]. Northeast Petroleum University, 2016. 
8. WU Yizhi. Research on Optimization Method of Layer Section Combined Parameter for Separated Layer Water Injection Design [J]. Science Technology and Engineering, 2012, 12(11): 27112714.

9. ZHANG Yurong. Research on the Variation Mechanism of Zonal Injection Reservoir Parameters and Dynamic Deployment of Injection Allocation Parameters [D]. Northeast Petroleum University, 2011.

10. FU Qingchun. The Technology Limits for Stratified Injection of Polymer Flooding in Sub-layers of Sabei Area [D]. Northeast Petroleum University, 2011.

11. LI Haifang, SHAN Luyao. Effective Improvement of the Effect of Oilfield Development By the Use of Subdivision Water Injection Adjustment Method [J]. Inner Mongolia Petrochemical Industry, 2010, 36(12): 153-158.

12. LIN Jing. Studies on Water Injection Well Subdivision Method during Ultra-high Water Cut Stage in South Region I [D]. Daqing Petroleum Institute, 2008.

13. GAO Hang. Pattern Restructuring to Improve Water Flood Development Effect Method Research [d]. Northeast Petroleum University, 2017.

14. XIA Bing. Research on Technology of Fine Stratified Injection and Its Application [J]. China Petroleum and Chemical Standard and Quality, 2017, 37(14): 177-178.

15. GAO Jing. Study on Water Injection Development Adjustment in X Fault Block Reservoir [D]. Southwest Petroleum University, 2017.

16. YANG Zhonggui, ZHANG Xiulin, and SONG Chengli. Matching Technology for Fine SeparateLayer Water Injection in Fuyu Oilfield [J]. Unconventional Oil \& Gas, 2016, 3(01): 57-60.

17. Yang, Chao; Xu, Xiaoming; Qi, Mei; Li, Yanlan; Han, Jie Source: Injector-producer connectivity identification and water injection optimization of mature oil fields in high water cut period. Zhongnan Daxue Xuebao (Ziran Kexue Ban)/Journal of Central South University (Science and Technology), $\mathrm{v} 46, \mathrm{n} 12, \mathrm{p}$ 4592-4601, December 1, 2015 Language: Chinese. 